\title{
ECONOMIC COSTS OF HOSPITALIZATION AND LENGTH OF STAY IN DIABETES WITH CO-EXISTING HYPERTENSION WITH CORRELATION TO LABORATORY INVESTIGATIONS: WHERE DOES INDIA STAND? A FIVE YEARS GROUND REPORT
}

\author{
Amit Sharma ${ }^{1}$, Ashish Baldi², and Dinesh Kumar Sharma ${ }^{3}$ \\ ${ }^{1}$ ISF College of Pharmacy \\ ${ }^{2}$ Maharaja Ranjit Singh Punjab Technical University \\ ${ }^{3}$ Roorkee College of Pharmacy
}

November 26, 2020

\begin{abstract}
Introduction: The coexistence of diabetes mellitus (DM) and hypertension (HTN) worsen clinical outcomes and contribute to increased morbidity and mortality. Objective: This study aims to analyze the length of stay and healthcare costs by calculating the direct and indirect costs of diabetes with co-existing hypertension in North India. Methods: A prospective observational study was conducted at the medicine department of the three different hospitals. Results: The patients' mean age was found to be $(\mathrm{M}=53.8, \mathrm{SD}=11.5)$ years. Out of 1914 patients, $53.65 \%$ were found female. Our study revealed that the median cost of medical supplies and equipment was found to be $21.2 \$$. The median cost of dialysis was found at $47.5 \$$; the median cost of hospitalization was found to be $142.6 \$$. The treatment's median direct cost was $188.5 \$$, followed by the overall median cost of 295.6 \$. The maximum overall cost of treatment was observed at $603.9 \$$. It was observed that that maximum LOS was found to be 14 days for patients having BPS between 140 to $159 \mathrm{mmHg}$ and BPD between 110- $119 \mathrm{mmHg}$, and minimum LOS was found to be 3.5 days. Conclusion: The present study highlighted that diabetes co-existing hypertension poses a high economic burden on patients. This study explored that highly significant result for BPS, BPD, FBS, and HbA1c, whereas the significant results were obtained when RBS is compared with LOS and treatment costs. Our study concluded that mean difference of $9.24 \$$ in patients having FBS: 261-290 mg/dl and > $290 \mathrm{mg} / \mathrm{dL}$. The LOS increases 6.57 days for patients with BPS between 140-159 mmHg compared to BPS between 180 -above $209 \mathrm{mmHg}$, which lower treatment costs by $-21.31 \$$. Keywords: Diabetes, Hypertension, length of stay, cost of treatment, direct medical cost, indirect medical cost
\end{abstract}

\section{Hosted file}

Manuscript .pdf available at https://authorea.com/users/243463/articles/495456-economic-costsof-hospitalization-and-length-of-stay-in-diabetes-with-co-existing-hypertension-withcorrelation-to-laboratory-investigations-where-does-india-stand-a-five-years-groundreport

\section{Hosted file}

Figures.pdf available at https://authorea.com/users/243463/articles/495456-economic-costsof-hospitalization-and-length-of-stay-in-diabetes-with-co-existing-hypertension-withcorrelation-to-laboratory-investigations-where-does-india-stand-a-five-years-groundreport 


\section{Hosted file}

Tables.pdf available at https://authorea.com/users/243463/articles/495456-economic-costsof-hospitalization-and-length-of-stay-in-diabetes-with-co-existing-hypertension-withcorrelation-to-laboratory-investigations-where-does-india-stand-a-five-years-groundreport 